\title{
Control of Leaf and Vein Development by Auxin
}

\author{
Enrico Scarpella ${ }^{1}$, Michalis Barkoulas ${ }^{2}$, and Miltos Tsiantis $^{2}$ \\ ${ }^{1}$ Department of Biological Sciences, University of Alberta, Edmonton AB, Canada \\ ${ }^{2}$ Department of Plant Sciences, University of Oxford, Oxford OX1 3RB, United Kingdom \\ Correspondence: enrico.scarpella@ualberta.ca, miltos.tsiantis@plants.ox.ac.uk
}

Leaves are the main photosynthetic organs of vascular plants and show considerable diversity in their geometries, ranging from simple spoonlike forms to complex shapes with individual leaflets, as in compound leaves. Leaf vascular tissues, which act as conduits of both nutrients and signaling information, are organized in networks of different architectures that usually mirror the surrounding leaf shape. Understanding the processes that endow leaves and vein networks with ordered and closely aligned shapes has captured the attention of biologists and mathematicians since antiquity. Recent work has suggested that the growth regulator auxin has a key role in both initiation and elaboration of final morphology of both leaves and vascular networks. A key feature of auxin action is the existence of feedback loops through which auxin regulates its own transport. These feedbacks may facilitate the iterative generation of basic modules that underlies morphogenesis of both leaves and vasculature.

Lof eaf eaf form and vascular patterns provide some of the most impressive examples of the comA xity of biological shapes generated in nature. A common feature of the development of the leaf lamina and vein networks is the repeated use of basic modules. For example, the iterative emergence of marginal leaf-shape elements, such as serrations, lobes, and leaflets (Fig. 1A-D), and the arrangement of successive orders of branched veins result in different types of leaf geometries and vascular patterns, respectively. Intriguingly, there is also congruence of leaf shape and vein layouts, such that, at least superficially, the pattern of vasculature formation is well aligned with the final geometry of the leaf lamina. These observations raise the questions of (1) what are the specific signaling pathways that sculpt leaf shape and vascular patterns, (2) to what degree lamina growth and vascular development share common genetic control, and finally (3) how coordination between leaf and vascular development is achieved and impacts on generation of final leaf shape and vein arrangement. Over the past 15 years, genetic approaches have led to substantial increase in our understanding of leaf and vascular development, and have provided good evidence that regulated activity of the small indolic growth regulator auxin provides important spatial cues for both processes. Such roles of auxin in different facets of

Editors: Mark Estelle, Dolf Weijers, Karin Ljung, and Ottoline Leyser

Additional Perspectives on Auxin Signaling available at www.cshperspectives.org

Copyright (C) 2010 Cold Spring Harbor Laboratory Press; all rights reserved; doi: 10.1101/cshperspect.a001511

Cite this article as Cold Spring Harb Perspect Biol 2010;2:a001511 
E. Scarpella, M. Barkoulas, and M. Tsiantis

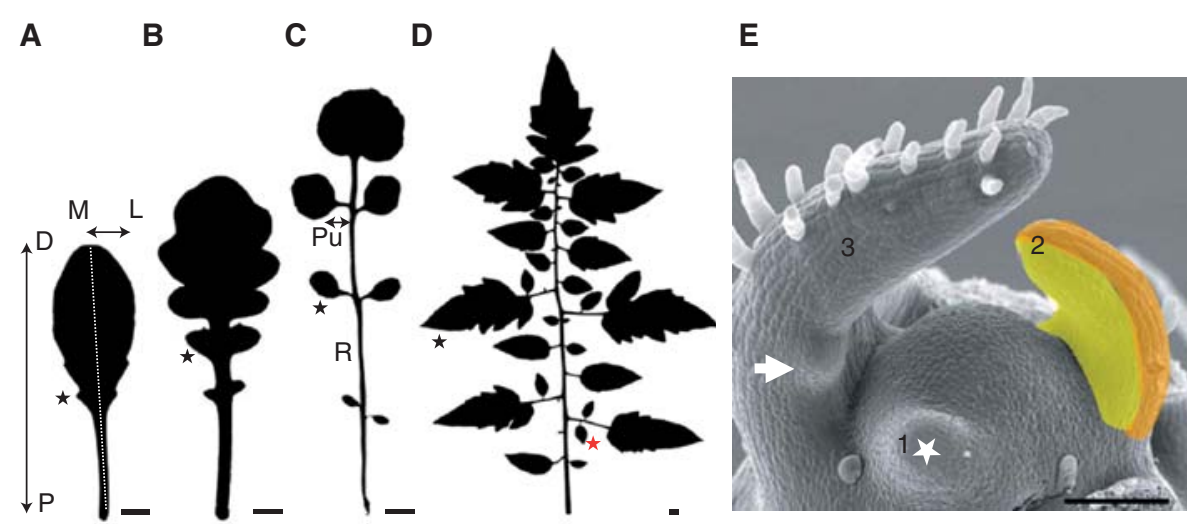

Figure 1. Axes of leaf asymmetry and diversity of leaf shape. (A) A simple, serrated leaf of the Columbia ecotype of Arabidopsis thaliana. The proximo-distal ( $\mathrm{P}-\mathrm{D})$ and medio-lateral $(\mathrm{M}-\mathrm{L})$ axes are indicated in the image. The asterisk marks one marginal serration. (B) The lobed leaf of the Arabidopsis thaliana relative Arabidopsis lyrata. The asterisk depicts the position of one lobe. Lobes are deep serrations, so the definition of an outgrowth as a serration or lobe is somewhat arbitrary. (C) The dissected leaf of Cardamine hirsuta. The asterisk marks a lateral leaflet. Leaflets are clearly defined as distinct units of the same leaf, which connect with the rachis $(\mathrm{R})$ via a structure called a petiolule $(\mathrm{Pu}) .(D)$ The dissected leaf of the cultivated tomato. Tomato demonstrates additional orders of dissection with respect to Cardamine hirsuta leaf and produces both primary leaflets (black asterisk) and secondary leaflets (red asterisk). (E) Scanning electron micrograph of the shoot apex of tomato. The white asterisk marks a leaf primordium (1) initiating from the meristem. The adaxial (yellow) and abaxial (orange) domains are marked on the subsequent developing leaf (2). Tomato is a compound leaf plant where leaflets are formed from the leaf blade soon after leaf initiation (a developing leaflet is marked by an arrow in leaf 3 ). Images in panels $A-D$ are leaf silhouettes. Scale bars: $(A-D) 1 \mathrm{~cm},(E) 100 \mu \mathrm{m}$.

leaf and vascular development is the focus of our article.

\section{LEAF AND VASCULAR DEVELOPMENT: A PRIMER}

Leaves are lateral organs that derive postembryonically from a pluripotent cell population at the tip of the plant, termed the shoot apical meristem (SAM) (Steeves and Sussex 1989). Leaf development begins with the specification of leaf founder cells at the flanks of the SAM, a process that happens in regular intervals and patterns. These cells will later grow into leaf primordia and finally form the mature flat leaves (Figs. 1E and 2). At very early stages of leaf development, which are often called "primary morphogenesis," the growth of the leaf is largely attributable to cell division. Once the basic leaf shape is established, cell division ceases, and leaves grow predominantly via cell expansion during the "secondary morphogenesis" phase (Donnelly et al. 1999; Dengler and Tsukaya 2001; Efroni et al. 2008) (Fig. 2 A-D). In addition to growth, a key event in the development of leaves is the correct differentiation of the several specialized cell types that underpin the physiological functions of the leaf, such as stomata for gas exchange, vascular cells for the transport of water and nutrients across the leaf, and mesophyll cells for photosynthesis. Although the cellular proliferation, differentiation, and expansion stages of leaf development cannot be rigidly separated in time, evidence has increasingly been accumulating that suggests that the temporal regulation of the transition from one stage to another is crucial for determining the final leaf shape (Ori et al. 2007; Efroni et al. 2008).

The vascular system of plants consists of a network of cell files (vascular strands) that extends through all organs (Esau 1965). In eudicot leaves, these vascular strands, or veins, are arranged in a ramified pattern that largely 


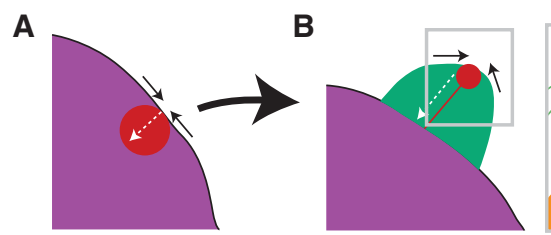

E

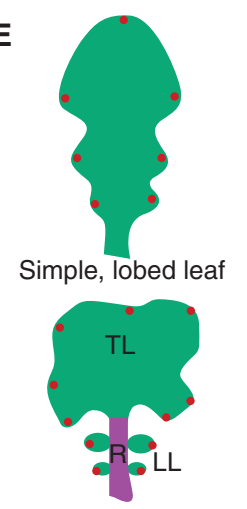

Dissected leaf
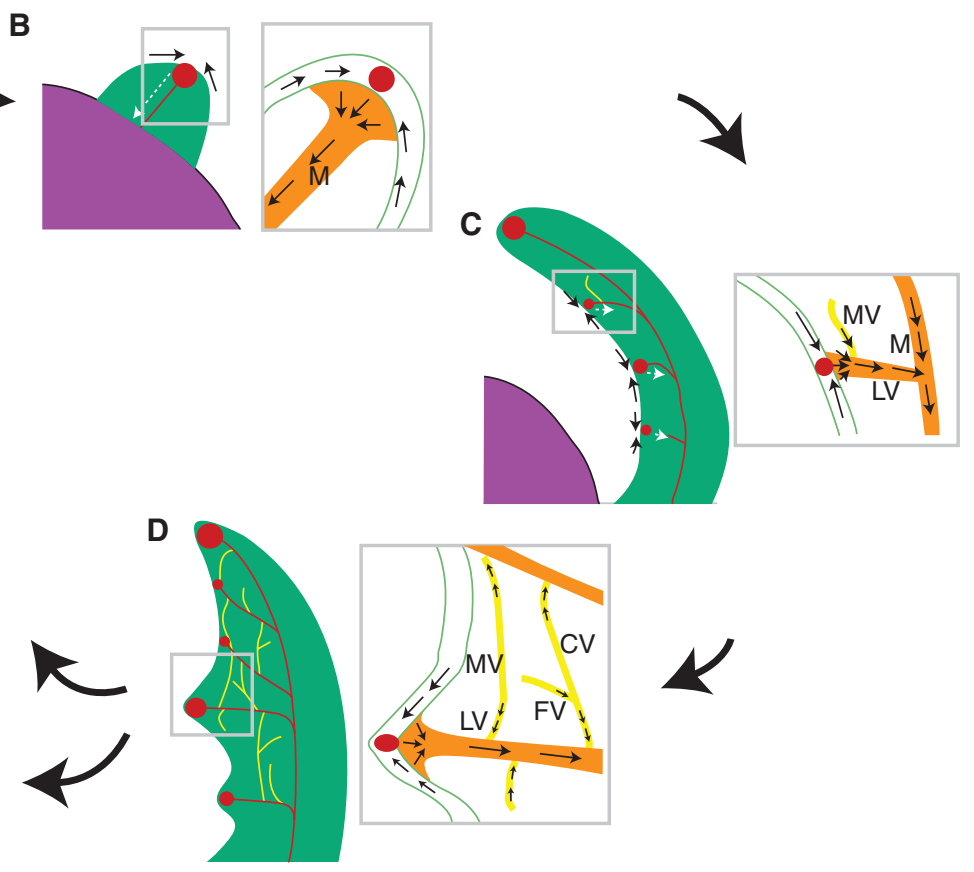

Figure 2. Stages of leaf development and associated polarities of auxin transport. (A) Leaf initials are specified at the flanks of the SAM (purple) and correspond to sites of elevated auxin activity (red) resulting from convergence points of PIN1 polarity in the epidermal layer (black arrows). From PIN1 convergence points, auxin is transported in internal tissues (white arrow), where it gradually induces formation of a vascular strand. (B) During leaf initiation, a small primordium (green) becomes visible at the flanks of the SAM. Epidermal auxin flow converges to form a maximum of auxin activity at the tip of the primordium. There, auxin is drained through the center of the primordium, marking the position of the midvein (orange, $\mathrm{M}$ ). (C) In primary morphogenesis, leaves grow predominantly via cell division to acquire their shape and vascular pattern. Auxin activity maxima at the margins of the leaf correlate with sites of lateral vein (orange, LV) formation and positions of serration development. Marginal veins (yellow, MV) emerge in continuity with lateral veins from PIN1 domains initiated within the growing lamina. Open-ended marginal vein precursors form the upper part of each vein loop and display uniform auxin transport polarity toward pre-existing lateral veins, but they switch to bipolarity as they become connected at both ends to give rise to closed vein loops. (D) After primary morphogenesis, the basic leaf and vasculature patterns are already formed. Similar to marginal veins, higher-order veins (yellow) have appeared in continuity with pre-existing vasculature from PIN1 domains initiated within the expanding blade. Higher-order veins can end freely in the lamina (FV) or become connected $(\mathrm{CV})$ on proximity to other PIN1 domains. During secondary morphogenesis, leaves grow primarily through cell expansion. (E) Examples of two basic leaf shapes, simple and dissected. In simple leaves, the leaf blade is composed of one unit (regardless of whether the leaf is smooth, serrated, or lobed), whereas, in dissected leaves, the blade is divided into distinct units called leaflets. The dissected leaf of the cartoon is similar to leaves of C. hirsuta, where the terminal leaflet (TL) is located at the tip of the leaf, whereas lateral leaflets (LL) are borne from the rachis (purple, R). Auxin activity maxima are present in both the lobes and serrations of the simple leaf and in the serrations of the terminal leaflet, but they are also associated with positions of lateral leaflet formation. Arrows within panels depict auxin flow, as inferred by PIN1 localization, whereas arrows between panels temporally connect successive stages of leaf formation. 
reflects the shape of the leaf (Nelson and Dengler 1997; Dengler and Kang 2001). Lateral veins branch from a conspicuous central vein (midvein) that is continuous with the stem vasculature (Fig. 2A-C). In many species, lateral veins extend along the leaf edge to form marginal veins, which connect to distal veins to form prominent closed loops (Fig. 2C,D). Finally, a series of higher-order veins branch from midvein and loops and can either terminate in the lamina (free-ending veins) or join two veins (connected veins) (Fig. 2D). All vascular cell types mature from procambial cells: narrow, cytoplasm-dense cells, characteristically arranged in continuous lines (Esau 1943). In the leaf, procambial strands differentiate from files of isodiametric "preprocambial" cells, which are selected from the anatomically homogeneous subepidermal ground tissue of the leaf primordium (Foster 1952; Pray 1955; Mattsson et al. 2003; Kang and Dengler 2004; Scarpella et al. 2004).

\section{LEAF INITIATION}

The plant growth regulator auxin has been implicated in the control of all of the previously mentioned stages of leaf development. Starting from leaf initiation, classical physiological experiments first suggested that auxin promotes leaf inception (Snow and Snow 1937). Loss of function in the Arabidopsis thaliana PINFORMED1 (PIN1) efflux facilitator compromises organogenesis at the SAM, as does pharmacological inhibition of auxin transport (Okada et al. 1991; Galweiler et al. 1998), and recent molecular work confirmed that leaf founder cells are characterized by elevated auxin activity that is largely generated by the delivery of auxin to the meristem via PIN1 (Reinhardt et al. 2000; Benkova et al. 2003; Reinhardt et al. 2003; Heisler et al. 2005). Paths of polar flow of the auxin signal seem to be accurately visualized through the subcellular localization of auxin exporters of the PIN family (Petrasek et al. 2006; Wisniewska et al. 2006), and PIN1 is apically localized at the epidermal cells of the SAM, directing auxin flow toward the summit of the meristem. The convergence of epidermal auxin flow creates auxin activity maxima at the periphery of the
SAM that mark the sites of initiating leaf primordia (Figs. 2A,B and 3). Concomitantly, basal PIN1 polarity in subepidermal cells of the incipient primordium is predicted to internalize auxin flow through the center of the leaf, defining the position of the future midvein (Reinhardt et al. 2003; Heisler et al. 2005) (Fig. 2A,B). Thus, both leaf and midvein formation are based on directional auxin transport, and factors that control PIN1 polarization are predicted to have a critical role in these two processes. Auxin overload (through direct auxin application or auxin transport inhibition) reduces separation between successively initiated leaf primordia (Okada et al. 1991; Bennett et al. 1995; Reinhardt et al. 2000). Although this observation suggests that positioning of convergence points is dependent on auxin supply and transport, a contribution of auxin uptake in stabilizing this process has more recently also been uncovered. Under specific environmental conditions and at specific developmental stages, simultaneous mutation in multiple members of the AUX1/LAX family of auxin importers results in reduced frequency and altered distribution of convergence points at the shoot apex, which are associated with spatially disorganized initiation of leaf primordia occurring in the absence of apparent alterations in shoot apex size and structure (Bainbridge et al. 2008).

Leaf initials act initially as sinks of auxin and deplete it from their proximity, thus inhibiting the initiation of additional leaf primordia at the periphery of the SAM. However, soon after their initiation, leaf primordia start to produce auxin, and this event is highlighted by a reversal in epidermal PIN1 polarity, so that auxin is transported back to the meristem to contribute to subsequent leaf initiation events (Ljung et al. 2001; Heisler et al. 2005). The underlying PIN1dependent mechanism that controls auxin distribution in the meristem has been proposed to be sufficient to explain the maintenance of the correct leaf initiation pattern termed phyllotaxis (Reinhardt et al. 2003), and quantitative modeling approaches based on auxin concentration, flow, and PIN1 polarization were successful to generate both the wild-type Arabidopsis leaf arrangements and the development of the midvein (de Reuille et al. 2006; Jonsson 


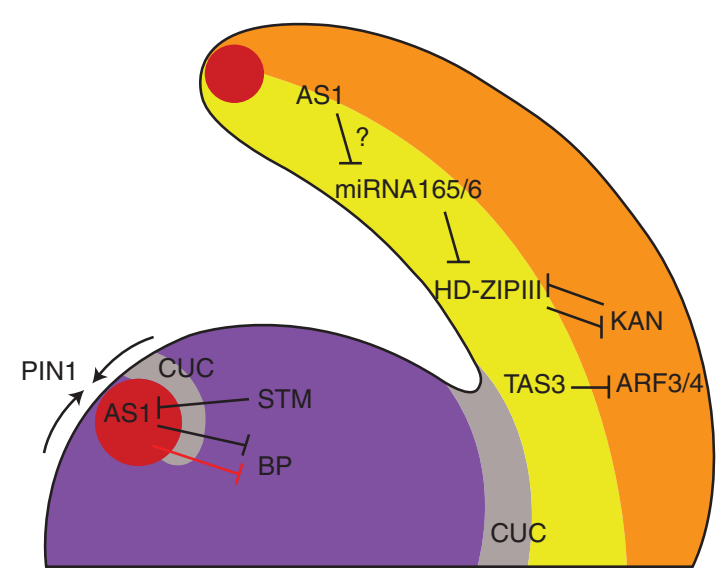

Figure 3. Model depicting interactions between auxin function components and key genetic pathways controlling leaf development in Arabidopsis thaliana. Convergence points of auxin flow (arrows) generated via polar PIN1 localization in epidermal cells contribute to establishing an auxin activity maximum (red dot) at the periphery of the SAM (purple). AS1 (together with the LOB domain protein AS2, not shown here) and auxin repress the $K N O X$ gene $B P$, thereby contributing to leaf outgrowth at the flanks of the SAM. The KNOX gene STM prevents AS1 expression in the meristem, thus establishing a mutually repressive interaction between meristem cells and leaf initials. Expression of STM might be regulated by auxin activity gradients, but this requires further investigation. CUC proteins (gray) are expressed at the boundary between meristem and leaf cells. The coordinated differentiation of abaxial and adaxial cell fates is critical for leaf function because it underpins functional specialization of the upper side (yellow), specialized for light capture, and a lower side (orange), specialized for gas exchange. Members of the HD-ZIP III class, such as $P H B$, promote adaxial fate and meristem activity, and are regulated by two known pathways. First, miRNA165/166 directly repress HD-ZIP III transcripts, which results in exclusion of HD-ZIP III expression from the abaxial domain and definition of HD-ZIP III expression level in the meristem and adaxial leaf domain. Second, expression of HD-ZIP III genes is repressed by the abaxial fate-promoting KAN proteins. The auxin response factors ARF3/ETT and ARF4 are required for KAN activity. ARF4 is expressed abaxially, whereas ARF3 mRNA may be more broadly distributed throughout the meristem and leaf primordia. Both $A R F 3$ and $A R F 4$ are subject to negative regulation by ta-siRNAs.

et al. 2006; Smith et al. 2006; Bayer et al. 2009). Finally, the action of auxin in leaf initiation is likely to be mediated by MONOPTEROS (MP), a transcription factor member of the AUXIN RESPONSE FACTOR (ARF) family, as $m p$ mutants show organ initiation defects similar to pin1 (Przemeck et al. 1996; Hardtke and Berleth 1998), and further reduction in auxin signaling or transport in the $m p$ mutant background abolishes leaf formation (Hardtke et al. 2004; Schuetz et al. 2008).

Together with localized auxin activity, another hallmark of the leaf initiation process in seed plants is the down-regulation of class I KNOTTED1-like homeobox (KNOX) genes within the population of leaf founder cells (Jackson et al. 1994; Long et al. 1996). Members of the KNOX gene family are expressed within the SAM region of all plant species, where they promote SAM activity, but their expression is excluded from leaf initials (Fig. 3). The repression of KNOX expression in the leaf is mediated by the ARP (ASYMMETRICLEAVES1 [AS1] in Arabidopsis/ROUGH SHEATH2 [RS2] in maize/ PHANTASTICA [PHAN] in snapdragon) MYB proteins (Waites et al. 1998; Timmermans et al. 1999; Tsiantis et al. 1999b; Byrne et al. 2000; Ori et al. 2000; Guo et al. 2008), which act as dimers with ASYMMETRIC LEAVES2-type LOB domain proteins (Semiarti et al. 2001; Xu et al. 2003; Evans 2007). Conversely, in A. thali$a n a$, the SHOOTMERISTEMLESS KNOX protein likely prevents AS1/2 activity in the SAM, indicating that mutual antagonism between AS and KNOX proteins helps distinguish leaf from meristem cells at the apex (Byrne et al. 
2000; Byrne et al. 2002) (Fig. 3). The nearly complementary expression patterns of KNOX and auxin activity reporters during early organ specification at the SAM suggested that auxin may also contribute to KNOX repression in leaves (Heisler et al. 2005). Further experiments supported this hypothesis, as inhibition of auxin transport or defective auxin signaling is sufficient to result in ectopic expression of the KNOX gene BREVIPEDICELLUS (BP) in leaves, whereas loss of $B P$ activity partially rescues the organogenic defects observed in pin1 mutants, indicating that ectopic $B P$ expression is partly responsible for the pin1 mutant phenotype (Hay et al. 2006). Conversely, ectopic KNOX expression in leaves decreases auxin transport and alters auxin activity distribution (Tsiantis et al. 1999a; Zgurski et al. 2005; Hay et al. 2006), suggesting mutually antagonistic interactions between KNOX and auxin action.

\section{LEAF AXIS FORMATION}

Following leaf initiation, the elaboration of leaf form involves the establishment of three axes of asymmetry, namely the proximo-distal, the medio-lateral, and the adaxial (upper side)abaxial (lower side) axis (Fig. 1A,E). The correct acquisition of cell fates along these different axes is fundamental for leaves to achieve the correct size and shape. In contrast to the adaxial-abaxial patterning, which has been quite extensively studied, relatively little information is known about the mechanisms that regulate the formation of the proximo-distal and medio-lateral axes of the leaf. Adaxial-abaxial patterning depends on mutual interactions between small RNAs and transcription factors that either promote adaxial or abaxial leaf fate (Bowman 2004; Barkoulas et al. 2007) (Fig. 3). Two key regulators of axial patterning appear to influence, and be influenced by, auxin activity (Fig. 3). These are class III HOMEODOMAIN-LEUCINE ZIPPER (HD-ZIP III) transcription factors, such as PHABULOSA (PHB), REVOLUTA (REV), and PHAVOLUTA (PHV), which are restricted to the adaxial side and promote adaxial fate, and proteins of the KANADI (KAN) family, which are expressed at the abaxial side and repress $H D-Z I P$
IIIs together with microRNA165/166. Auxin signaling has been shown to contribute to this axial patterning pathway as two auxin response factors, ARF3/ETT and ARF4, act together with KANs to promote abaxial fate (Pekker et al. 2005). ARF4 is expressed at the abaxial side of leaf primordia, suggesting that a localized auxin response may underpin leaf polarity. Both ARF4 and the more broadly expressed $A R F 3$ transcript are negatively regulated by trans-acting small interfering RNAs, which thus contribute to distinction of abaxial and adaxial cell types in the leaf (Pekker et al. 2005; Fahlgren et al. 2006; Garcia et al. 2006; Hunter et al. 2006; Chitwood et al. 2009). The KAN/HD-ZIP III module may also provide input into auxin-based patterning via modulation of PIN activity, as defects in PIN1 expression are observed in embryonic tissues when members of either the KAN or HD-Zip III gene families are compromised (Izhaki and Bowman 2007). These ideas are further strengthened by the observations that mutations in the APETALA2 transcription factor DORNROSCHEN (DRN), a likely cofactor of PHV, perturb auxin response and PIN1 expression (Chandler et al. 2007). Because DRN is a direct target of the MP auxin response factor in cotyledons (Cole et al. 2009), it is possible that a transcriptional response to auxin influences activity of HD-ZIP III/DRN-containing protein complexes, thus suggesting a tight auxin/HD-ZIP III/DRN feedback loop. Notably, the KAN/ HD-ZIP III developmental module also provides direct input in vasculature development, as HDZIP IIIs and KANs are also involved in the radial patterning of the vascular bundles. In mature veins, vascular tissues are organized in bundles with phloem tissue at the abaxial side of the bundle juxtaposed to xylem tissue located at the adaxial pole of the bundle. Triple mutants in the HD-ZIP III genes PHB, PHV, and REV develop abaxialized leaves in which xylem is surrounded by phloem ("abaxialized" veins), whereas gain of function of HD-ZIP IIIs or kan 1; kan2; kan3 triple mutants develop adaxialized leaves and vascular bundles (Carlsbecker and Helariutta 2005).

Finally, it is important to note that because adaxial/abaxial juxtaposition is fundamental for driving leaf growth (Waites et al. 1998), 
the involvement of auxin in axial patterning pathways is likely to indirectly influence leaf growth. However, auxin has long been known to regulate growth in a more direct fashion; indeed, the molecule's name is derived from the greek "auxein," i.e., to grow, as the compound was first identified as a potent regulator of plant growth responses. Auxin can modulate both cell division and expansion, and physiological evidence suggests that the proliferation or expansion responses to auxin can be uncoupled (Haber 1962; Bhalerao and Bennett 2003). Such more direct effects of auxin on cellular growth in the leaf are mediated by two distinct signaling pathways: first, a well-characterized TRANSPORT INHIBITOR RESPONSE1 (TIR1)- AUXIN/INDOLE-3-ACETIC ACID (AUX/IAA)ARF dependent pathway (Dharmasiri et al. 2005; Wilmoth et al. 2005; Leyser 2006; Schruff et al. 2006); second, a much less well understood pathway involving the ER-localized protein AUXIN BINDING PROTEIN1 (ABP1), which can act as an auxin receptor in parallel to TIRs (Chen et al. 2001a; Chen et al. 2001b; Braun et al. 2008). Further study of these effects of auxin on cellular growth and the relationship between these two pathways will be a very exciting area of future research, but is outside the scope of this article.

\section{GENERATION OF LEAF SHAPE}

Correct auxin transport is not only required for the formation of leaves, but it is also pivotal for the development of marginal outgrowths that sculpt the final leaf shape. In Arabidopsis, perturbations of auxin transport result in leaves that fail to initiate the characteristic marginal projections, called serrations (Hay et al. 2006). Absence of marginal configurations on inhibition of auxin transport is similarly observed in leaves that normally produce deep lobes in response to ectopic KNOX expression (Zgurski et al. 2005; Hay et al. 2006). Epidermal PIN1 convergence points define local auxin activity maxima at the tips of forming serrations or lobes (Hay et al. 2006; Scarpella et al. 2006) (Fig. 2C). Therefore, the auxin dependent mechanism that triggers leaf initiation at the flanks of the SAM may be later redeployed within leaves to elaborate leaf shape. Basal PIN1 polarity in subepidermal cells of the marginal outgrowth is then predicted to internalize auxin through the center of the serration or lobe, defining the sites of lateral vein formation (Fig. 2C). Thus, similarly to the tight association between leaf and midvein formation, marginal outgrowths of the leaf primordium and positioning of lateral veins seem to be anchored to one another through epidermal PIN1 convergence points (Hay et al. 2006; Scarpella et al. 2006; Wenzel et al. 2007).

Regulated auxin transport also plays a crucial role for the elaboration of more complex leaf forms, such as the dissected leaf, where in contrast to the simple and undivided leaf blade of Arabidopsis, the leaf is divided into distinct leaflets (Fig. 1A, C-E). Pharmacological perturbations of auxin transport in tomato and pea, in which dissected morphology evolved independently and requires different molecular toolkits, revealed a striking conversion from the complex leaf shape into a simple one (Avasarala et al. 1996; DeMason and Chawla 2004; DeMason 2005; Wang et al. 2005). More recently, PIN1mediated auxin transport was shown to be required for the formation of lateral leaflets in C. hirsuta, a dissected-leaf relative to Arabidopsis, suggesting a broad role for auxin efflux in leaflet formation of plant lineages where dissected leaves evolved independently, a role further underlined by observations that PIN1-mediated auxin efflux also facilitates leaflet initiation in tomato (Bharathan et al. 2002; Champagne et al. 2007; Barkoulas et al. 2008; Koenig et al. 2009). Lateral leaflet formation in C. hirsuta involves the generation of marginal cell division foci, which are formed postinitiation of the leaf and in response to PIN1-dependent local auxin activity maxima (Barkoulas et al. 2008). The mechanistic conservation of at least some of the regulatory components required for the development of serration, lobes, and leaflets indicates a morphological continuity in leaf margin complexity (Fig. 1A-D), but also highlights differences in the consequences of PIN1 action in different tissue contexts. Thus, in C. hirsuta, the PIN1/auxin module supports the generation of leaflets that arise via new 
cell divisions from the leaf rachis in the absence of previous lateral growth. Contrastingly, PIN1dependent marginal serrations in Arabidopsis develop in the context of pre-existing lateral growth of the lamina. Therefore, the action of PIN1 in sculpting the serration of the Arabidopsis leaf may reflect later polarization of growth of more limited pools of cells at the leaf margin, as opposed to polarization of growth of the entire population of cells giving rise to lateral leaflets in C. hirsuta. At least part of the species-specific ability of PIN1 activity to promote leaflet formation may result from interactions of auxin and KNOX-dependent processes because KNOX proteins are expressed in the C. hirsuta rachis and leaves of other dissected leaf species (Hareven et al. 1996; Bharathan et al. 2002; Hay and Tsiantis 2006), but they are excluded from simple leaves such as those of $A$. thaliana. KNOX proteins promote leaflet formation in a pathway that requires PIN1-dependent auxin efflux, whereas KNOX transcription itself may be repressed by high auxin activity along the rachis margins (Barkoulas et al. 2008). These observations indicate that $\mathrm{KNOX} /$ auxin interactions similar to those operating in the SAM may also be deployed later in development of dissected leaves to generate leaflets, thus creating a flexible framework of which evolutionary tinkering might have led to many of the complex leaf forms apparent in nature.

These issues also highlight current problems in the area and illustrate the need to determine the precise sequence of events through which auxin influences leaf shape. There is some evidence that AUX/IAA-ARF-dependent signaling facilitates correct leaflet formation in tomato. Mutations in the putative auxin response repressor IAA9/ENTIRE result in simple leaves with high degree of leaflet fusions (Wang et al. 2005; Zhang et al. 2007; Koenig et al. 2009), indicating a role for auxin in leaflet separation, and similar defects are observed on inhibition of auxin transport (Wang et al. 2005; Barkoulas et al. 2008). Interestingly, auxin transport inhibition results in reduced spacing of epidermal convergence points in the leaf and reduced separation between successively initiated leaf primordia, indicating a functional similarity between vein positioning in the leaf, primordium formation at the shoot apex, and leaflet formation from the leaf (Okada et al. 1991; Bennett et al. 1995; Mattsson et al. 1999; Sieburth 1999; Reinhardt et al.2000; Scarpella et al.2006). Defects in leaflet delimitation are also observed in C. hirsuta plants that have reduced activity of the three CUP-SHAPED COTYLEDON (CUC) genes (Blein et al. 2008), or in loss-of-function mutations in the tomato ortholog of CUC2, known as GOBLET (Berger et al. 2009). CUC genes encode transcription factor members of the NO APICAL MERISTEM (NAC) family that act together to restrict outgrowth initiation both in the SAM and leaf margins (Aida et al. 1997; Takada et al. 2001; Vroemen et al. 2003; Hibara et al. 2006; Nikovics et al. 2006; Blein et al. 2008; Berger et al. 2009). Auxin modulates CUC expression in the Arabidopsis embryo (Vernoux et al. 2000; Aida et al. 2002; Furutani et al. 2004); thus, it is possible that the effects of auxin on leaflet delimitation occur through regulation of CUC expression, or vice versa that CUC proteins modulate PIN1 expression or auxin response to facilitate leaflet formation. Because the mechanisms regulating auxin levels and auxin-mediated responses were already present in early land plants (Cooke et al. 2002), the finding that PIN1 is required for both serrations and the generation of the dissected leaf form suggests that the evolution of multiple types of tissue outgrowths may have been constrained or canalized by the ability to regulate marginal auxin activity gradients. Similarly, CUC proteins appear strictly required for generation of marginal serrations or leaflets in a range of very distantly related eudicots despite the independent evolutionary origins of compound leaves studied (Blein et al. 2008). These striking observations raise the interesting possibility that the CUC/auxin developmental module represents an "obligatory" evolutionary path for polarizing marginal growth and producing diverse leaf shapes.

\section{PREPROCAMBIAL CELL SELECTION}

Primary leaf morphogenesis temporally coincides with formation of major veins (i.e., the midvein and lateral veins), and a suite of mutants exist 
in which leaf shape and vascular pattern defects are coupled (Dengler and Kang 2001). These observations suggest that either the same factors regulate leaf morphogenesis and vein patterning or that the two processes influence one another. Although the interdependency between leaf form acquisition and vascular pattern formation remains largely unexplored, just as for leaf development, intertwined pathways of auxin transport and signal transduction have long been implicated in controlling all stages of vascular strand formation.

A variety of substances have been reported to promote vascular differentiation (Fukuda 2004), but the role of auxin in this process is unique. Auxin is the only molecule that not only triggers vascular cell differentiation, but also induces vascular strand formation, a response with distinctive and reproducible properties (Sachs 1981; Berleth et al. 2000). Application of auxin to plant tissues results in formation of new vascular strands that connect the auxin source with pre-existing vasculature. The auxin-induced vascular differentiation response is: (1) local, as vascular strand formation is initiated at the specific site of auxin application; (2) polar, as vascular strand formation progresses from the auxin source toward the basal side of the plant; (3) continuous, as it generates uninterrupted files of vascular cells; (4) constrained in the planes perpendicular to the main axis of the vascular differentiation response, as it originates multiple, slender bundles of vascular cell files; and (5) dependent on auxin flow, as it requires efficiently transported auxins and is obstructed in the presence of auxin transport inhibitors. The capability of a simple signal to trigger a complex and oriented cellular response such as that of vascular strand formation suggests that the underlying mechanism recruits directional cues already present in the organism. Because, in the plant, auxin is synthesized predominantly in young apical regions, such as leaf primordia and floral buds, and transported basally (Michniewicz et al. 2007), the source of asymmetric information co-opted by the auxin-induced vascular differentiation response probably coincides with the polar flow of auxin itself.

Expression profiling identifies PIN1 as the most relevant member of the PIN gene family in leaf vein formation (Scarpella et al. 2006). During normal and experimentally altered leaf vein formation, PIN1 expression in subepidermal cells precedes and converges toward sites of preprocambial strand formation and, at the PIN1 expression level, all veins appear to be generated through two basic ontogenies (Scarpella et al. 2006; Wenzel et al. 2007) (Figs. 2B-D and 4A). The midvein and lateral veins originate from subepidermal PIN1 domains associated with convergence points of PIN1 polarity in the epidermis, whereas higher-order veins emerge from PIN1 domains initiated within the expanding lamina. These internal domains are initially free-ending, but can become connected on proximity to other PIN1 domains. Interestingly, individual loops are composed of a lateral PIN1 domain, which is initiated at an epidermal convergence point, and a marginal domain, which is ontogenically equivalent to a connected higher-order PIN1 domain (Figs. 2C,D and 4A). In mature leaves, the composite origin of the first and second loop pairs is obscured by the smooth amalgamation of lateral and marginal veins, but this origin can be recognized in third and subsequent loop pairs (Kang and Dengler 2004; Scarpella et al. 2006) (Fig. 2D).

Elevated auxin levels, occurring naturally in association with serration tips or experimentally as a consequence of either direct auxin application or auxin transport inhibition, lead to the expansion of PIN1 expression domains (Aloni et al. 2003; Mattsson et al. 2003; Hay et al. 2006; Scarpella et al. 2006; Wenzel et al. 2007) (Fig. 4A). Broad PIN1 domains eventually taper to a few cell files that predict vein position, and this narrowing process is dependent on auxin transport. Subcellular PIN1 localization indicates that PIN1 polarity may not be uniformly directed toward pre-existing veins across wide PIN1 domains, but it is usually so along each domain's midline. Within narrow PIN1 domains, subcellular localization indicates auxin transport toward pre-existing veins: In free-ending domains a single polarity exists, whereas in connected domains two opposite polarities are connected by a bipolar cell (Scarpella et al. 2006; Wenzel et al. 2007). Although paths of auxin flow seem to define sites of vein formation, proper auxin perception should be required for 
E. Scarpella, M. Barkoulas, and M. Tsiantis

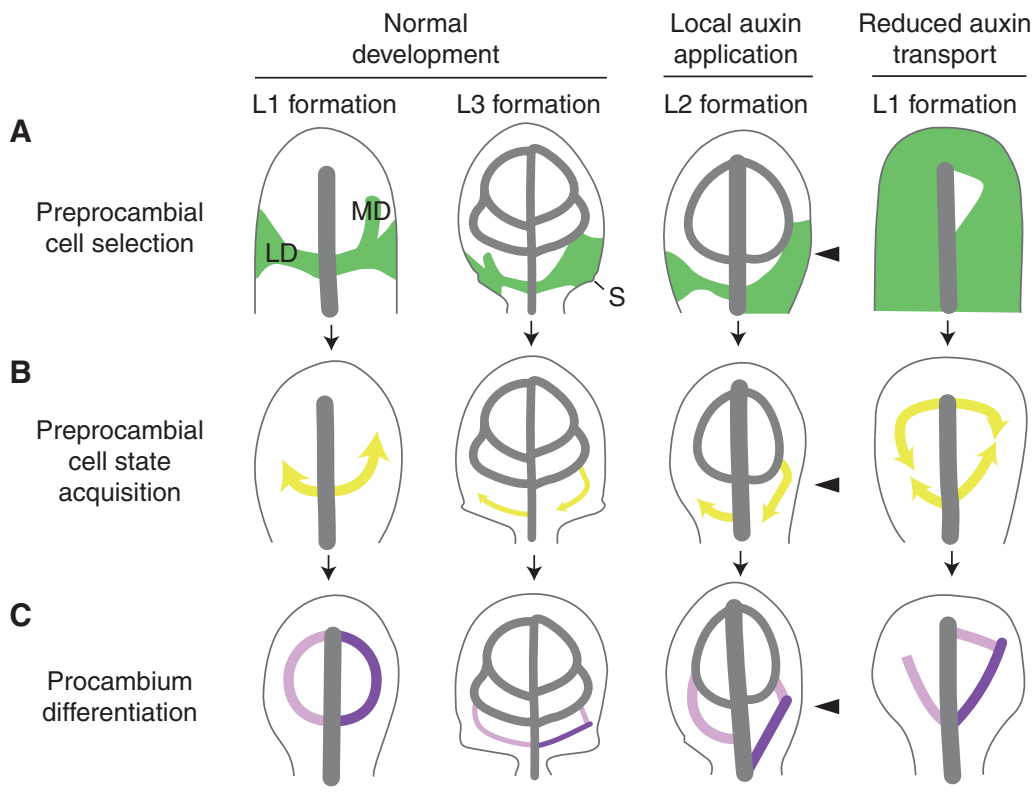

Figure 4. Control of leaf vein formation by polar auxin transport. Stage-specific dynamics of leaf vein patterning and dependency on auxin levels and flow as exemplified for loop formation, but in general equally applicable to all veins. (A) PIN1-labeled auxin transport paths corresponding to preprocambial cell selection zones (green). Note how loops are composed of a lateral PIN1 expression domain (LD) and an initially free-ending marginal PIN1 expression domain (MD). Further, note slightly expanded PIN1 expression domains in a fraction of serration tip-associated third loops during normal development, broad PIN1 domains on the side of local auxin application (arrowhead), and nearly ubiquitous PIN1 expression on systemic auxin flow inhibition. (B) Directions of ATHB8-defined preprocambial strand formation (yellow arrows). Note middle-to-margin progression of preprocambial strand formation during normal loop development. Further, note marginto-middle preprocambial strand extension in a fraction of third loops during normal development and in all loops forming on the side of auxin application. Finally, note coexistence of middle-to-margin and marginto-middle polarities of preprocambial strand extension during the formation of individual loops in response to auxin transport inhibition. $(C)$ Gradual appearance of procambial cell identity acquisition (light to dark purple). Note simultaneous differentiation of lateral and marginal procambial strands in normal loop development. Further, note successive formation of lateral and marginal procambial strands in a fraction of third loops during normal development and in all loops formed on the side of auxin application and under conditions of reduced auxin transport. Arrows temporally connect successive stages of vein formation. L1, L2, and L3, first, second, and third loops, respectively. See text for additional details.

triggering vascular differentiation. Consistent with this observation, severely compromised auxin signaling in $m p$ mutants (Mattsson et al. 2003) is associated with simplified vein networks (Przemeck et al. 1996) and reduced levels of PIN1 expression in the leaf (Wenzel et al. 2007).

These observations are consistent with the notion that vasculature is formed along core areas of gradually restricted domains of elevated auxin transport (Mitchison 1980; Sachs 1989; Rolland-Lagan and Prusinkiewicz 2005). However, traditional models of auxin transport, which rely on high levels of auxin exporter expression in cells specialized for auxin transport, simulate auxin depletion from developing veins. These predictions are difficult to reconcile with experimental evidence suggesting that veins develop along paths of maximum auxin levels (Mattsson et al. 2003; Scarpella et al. 2004; Scarpella et al. 2006), but supplementing conventional auxin export-based models with carrier-mediated auxin uptake seems to be sufficient to maintain high auxin concentrations within developing veins (Kramer 2004). Although auxin still 
remains "invisible" at the cellular level, this hypothesis can now be experimentally evaluated as multiple mutant combinations of members of the AUX1/LAX family of auxin importers have recently become available (Bainbridge et al. 2008).

\section{PREPROCAMBIAL CELL STATE ACQUISITION}

During the formation of all veins and under all tested experimental conditions, expression of preprocambial cell state markers such as the HD-ZIP III gene ATHB8 is initiated next to pre-existing vasculature and extends progressively away from its point of origin (Kang and Dengler 2004; Scarpella et al. 2004; Sawchuk et al. 2007), suggesting that all veins arise as free-ending preprocambial branches (Fig. 4B). Furthermore, connected veins form by fusion of initially free-ending preprocambial strands with other free-ending or connected strands, whereas free-ending veins result from termination of the extension of preprocambial expression domains (Scarpella et al. 2004; Sawchuk et al. 2007) (Fig. 4B).

Under all conditions, preprocambial strands extend progressively, although the specific direction of this progression varies. Preprocambial strands in the first and second loop pairs invariably extend from central to marginal regions of the developing leaf, whereas third loop preprocambial strands can form in the opposite direction (i.e., marginal to central) (Sawchuk et al. 2007) (Fig. 4B). Unlike the first and second loop pairs, third loop pairs are associated with expanded PIN1 subepidermal domains and conspicuous auxin response maxima at the primordium margin (Aloni et al. 2003; Mattsson et al. 2003; Hay et al. 2006; Scarpella et al. 2006; Wenzel et al. 2007) (Fig. 4B). This suggests that preprocambial strands are initiated at a critical auxin level, which for third and subsequent loop pairs could be attained at the margin of the primordium, possibly because of localized auxin synthesis (Cheng et al. 2006). In contrast, auxin levels critical for initiation of preprocambial strands of the first two loop pairs would be achieved at the center of the primordium, in proximity of the midvein, presumably where auxin produced throughout the lamina converges. This interpretation is further supported by the observation that direct auxin application at the primordium margin results solely in margin-to-middle polarity of preprocambial strand formation (Sawchuk et al. 2007) (Fig. 4B). Moreover, when auxin levels are uniformly increased throughout the primordium because of reduction in auxin flow, individual loops can even be formed by fusion of two preprocambial strands extending with opposed polarities (Sawchuk et al. 2007) (Fig. 4B).

\section{PROCAMBIUM DIFFERENTIATION}

Expression of procambial differentiation markers suggests that procambium distinctive features appear simultaneously along entire strands (Mattsson et al. 1999; Scarpella et al. 2004; Sawchuk et al. 2007) (Fig. 4C). Preprocambial cells within an individual strand acquire the stereotypically narrow shape of procambium through coordinated elongation, rather than through synchronized cell division parallel to the axis of the preprocambial strand (Donnelly et al. 1999; Kang and Dengler 2002; Sawchuk et al. 2007).

Although procambium differentiates simultaneously along the complete loop in the first two loop pairs, lateral and marginal procambial strands can appear successively in third loops (Sawchuk et al. 2007) (Fig. 4C). As formation of third loop pairs is associated with increased auxin levels at serration tips (Aloni et al. 2003; Mattsson et al. 2003; Cheng et al. 2006; Hay et al. 2006; Scarpella et al. 2006), excess auxin seems to prevent simultaneous procambium differentiation along entire loops. This hypothesis is also supported by the observation that lateral and marginal procambial strands appear separately in all looplike veins formed in response to auxin application (Sawchuk et al. 2007) (Fig. 4C). Furthermore, when auxin levels are raised in the primordium through auxin transport inhibition, differentiation of lateral and marginal strands occurs in temporally distinct steps for all loops, including the first two loop pairs, which typically undergo simultaneous differentiation (Sawchuk et al. 2007) (Fig. 4C). Augmented auxin levels could lead to deviations in simultaneity 
of procambial loop differentiation by delaying the transition of incipient lateral veins from less efficient to more efficient auxin sinks. This, in turn, would defer the formation of marginal veins connecting lateral veins to pre-existing vasculature, which is similar to what is observed in other organs (Sachs 1968). The simultaneous differentiation of lateral and marginal procambial strands in first and second loop pairs observed under normal conditions could thus simply reflect efficient auxin flow and/or inconspicuous auxin synthesis in early primordium development.

\section{TERMINATION OF VEIN FORMATION}

Termination of vein formation could, in principle, occur at any developmental stage; however, available evidence suggests that, although formally possible, termination is unlikely to occur at the procambial stage. In fact, all the mutants isolated to date with fragmented vein patterns show defects in continuity of ATHB8 preprocambial expression domains in the presence of initially uninterrupted files of PIN1-selected preprocambial cells (Carland et al. 1999; Deyholos et al. 2000; Koizumi et al. 2000; Carland and Nelson 2004; Scarpella et al. 2006; Naramoto et al. 2009). Furthermore, mutants with fewer procambial strands, a higher proportion of which end freely, display comparable reduction in complexity and connectivity of $A T H B 8$ expression domains (Candela et al. 1999; Alonso-Peral et al. 2006; Cnops et al. 2006; Petricka and Nelson 2007). These observations suggest that termination of vein formation must have occurred during preprocambial cell state acquisition. Termination of preprocambial strand formation has, in turn, been suggested to be a product of exhausted signaling within the developing veins (Carland et al. 1999; Steynen and Schultz 2003; Carland and Nelson 2004; Motose et al. 2004) and/or consumptive differentiation of the remaining ground meristem population into the alternative subepidermal tissue of the mature leaf, the mesophyll (Scarpella et al. 2004; Kang et al. 2007). Whether these different mechanisms are elements of the same pathway will have to await the identification of more molecular components.

\section{A MATTER OF CONTEXT?}

The work discussed previously shows that feedback mechanisms through which auxin regulates its own flow form the basis for a versatile, repeatedly deployed developmental module that underpins leaf and vascular development and facilitates sequential generation of self-similar elements of pattern for both tissue types. However, this common "auxin activity" module is hardwired in different developmental contexts, determined, at least in part, by specific transcription factors, such as, for example, KNOX and AS1 in the SAM, HD ZIP IIIs and KANs in lateral organs, embryos and vasculature, KNOX in dissected leaves, and PLETHORAs in the roots (Galinha et al. 2007). In all of these instances, evidence exists for feedback loops between auxin action and the "patterning/organ identity" transcription factors. A key challenge for the future will therefore be to understand the precise organization of these feedbacks and elucidate how their cell-specific readouts direct leaf and vascular development.

\section{CONCLUDING REMARKS}

Pieces of the puzzle of how different leaf shapes and vein patterns are generated have started to emerge; however, many questions remain unanswered. Although there is good evidence that placement of leaf primordia at the shoot apex and location of midvein, as well as positioning of lateral veins and marginal outgrowths within developing leaves, are associated with epidermal convergence points of auxin flow, the molecular mechanism underlying generation and positioning of such convergence points remains elusive. The existence of bipolar cells provides a possible explanation to reconcile polarity of auxin flow with closed vein networks, in which most veins are connected to others at both ends with no obvious polarity, but are bipolar cells located at fixed positions within individual connected veins or does their position along the course of each vein change over time? And do those cells represent local sources of auxin? Successive stages of vein formation emerge with strikingly different dynamics: Broad domains 
of preprocambial cell specification are constrained to narrow zones; preprocambial cell state acquisition is propagated progressively in individual cell files; and procambial cell identity is assigned simultaneously to all the cells along a developing vein. How are the developmental dynamics of one stage translated into those characteristic of the subsequent stage? Expression of preprocambial and premesophyll markers identify two nonoverlapping cell states (Sawchuk et al. 2008), and a key question for the future will be to understand the degree to which developmental decisions made in vein-forming cells are coordinated with decisions made in nonvascular tissues. It is likely that the vascular system provides a scaffold that influences growth of the lamina. Such influence could be provided by chemical signals emanating from developing veins, or alternatively, it is possible that mechanical stress generated during vascular strand formation provide cues to neighboring lamina cells that influence direction and rate of growth. The opposite scenario is also possible where areas of localized growth in the leaf drive the formation of major veins. Resolution of this problem will require the use of genetic analysis to delineate differences and similarities in the auxin signaling pathways directing lamina and vascular development in a variety of simple and dissected-leaf species. It will further require rigorous documentation of interdependence of vasculature and lamina development using dynamic phenotyping systems and computational modeling that capture essential elements of the process of leaf development and formalize their interactions in quantitative frameworks. Further, it will be interesting to determine the mechanistic basis for integration of the different facets of auxin activity in leaf and vascular development, and how such integration ultimately generates the multitude of venation patterns and leaf shapes apparent in nature. Notably, conclusions presented here are based on work on model eudicot species. However, leaves of other seed plants can present radically different shapes and vascular patterns, such as the strap-shaped leaves of monocot grasses with parallel venation. Although at least some components of the molecular pathways that translate auxin into morphological readouts are conserved between core eudicots and grasses (see McSteen 2010), further work is required to evaluate the extent of this similarity and how it relates to divergent taxon-specific morphologies. Although the answers to these and other questions still elude us, the recent work reviewed here has originated a scaffold of hypotheses and derived predictions that can be directly tested in the near future.

\section{ACKNOWLEDGMENTS}

We thank Carla Galinha for help with drawing Figure 3. We apologize to colleagues whose results could not be included in the available space. This work was supported by a Discovery Grant of the Natural Sciences and Engineering Research Council of Canada (E.S.), by an Alberta Ingenuity New Faculty Grant (E.S.), and by the Canada Research Chairs Program (E.S.). This work was also funded by the Biotechnology and Biological Sciences Research Council (BBSRC) BB/F012934/1 (M.T. and M.B.) and the Gatsby Foundation (M.T). M.T. is a recipient of an EMBO Young Investigator Award and a Royal Society Wolfson Merit award.

\section{REFERENCES}

Aida M, Ishida T, Fukaki H, Fujisawa H, Tasaka M. 1997. Genes involved in organ separation in Arabidopsis: An analysis of the cup-shaped cotyledon mutant. Plant Cell 9: $841-857$.

Aida M, Vernoux T, Furutani M, Traas J, Tasaka M. 2002. Roles of PIN-FORMED1 and MONOPTEROS in pattern formation of the apical region of the Arabidopsis embryo. Development 129: 3965-3974.

Aloni R, Schwalm K, Langhans M, Ullrich CI. 2003. Gradual shifts in sites of free-auxin production during leafprimordium development and their role in vascular differentiation and leaf morphogenesis in Arabidopsis. Planta 216: $841-853$

Alonso-Peral MM, Candela H, del Pozo JC, Martinez-Laborda A, Ponce MR, Micol JL. 2006. The $H V E / C A N D 1$ gene is required for the early patterning of leaf venation in Arabidopsis. Deveopment 133: 37553766.

Avasarala S, Wang J, Caruso JL. 1996. Production of phenocopies of the lanceolate mutant in tomato using polar auxin transport inhibitors. J Exp Bot 47: 709-712. 
Bainbridge K, Guyomarc'h S, Bayer E, Swarup R, Bennett M, Mandel T, Kuhlemeier C. 2008. Auxin influx carriers stabilize phyllotactic patterning. Genes Dev 22: 810-823.

Barkoulas M, Galinha C, Grigg SP, Tsiantis M. 2007. From genes to shape: Regulatory interactions in leaf development. Current Opinion Plant Biol 10: 660-666.

Barkoulas M, Hay A, Kougioumoutzi E, Tsiantis M. 2008. A developmental framework for dissected leaf formation in the Arabidopsis relative Cardamine hirsuta. Nat Gen 40: 1136-1141.

Bayer EM, Smith RS, Mandel T, Nakayama N, Sauer M, Prusinkiewicz P, Kuhlemeier C. 2009. Integration of transport-based models for phyllotaxis and midvein formation. Genes Dev 23: 373-384.

Benkova E, Michniewicz M, Sauer M, Teichmann T, Seifertova D, Jurgens G, Friml J. 2003. Local, efflux-dependent auxin gradients as a common module for plant organ formation. Cell 115: 591-602.

Bennett SRM, Alvarez J, Bossinger G, Smyth DR. 1995. Morphogenesis in pinoid mutants of Arabidopsis thaliana. Plant J 8: 505-520.

Berger Y, Harpaz-Saad S, Brand A, Melnik H, Sirding N, Alvarez JP, Zinder M, Samach A, Eshed Y, Ori N. 2009. The NAC-domain transcription factor GOBLET specifies leaflet boundaries in compound tomato leaves. Development 136: 823-832.

Berleth T, Mattsson J, Hardtke CS. 2000. Vascular continuity and auxin signals. Trends Plant Sci 5: 387-393.

Bhalerao RP, Bennett MJ. 2003. The case for morphogens in plants. Nat Cell Biol 5: 939-943.

Bharathan G, Goliber TE, Moore C, Kessler S, Pham T, Sinha NR. 2002. Homologies in leaf form inferred from KNOXI gene expression during development. Science 296: 1858 1860.

Blein T, Pulido A, Vialette-Guiraud A, Nikovics K, Morin H, Hay A, Johansen IE, Tsiantis M, Laufs P. 2008. A conserved molecular framework for compound leaf development. Science 322: 1835-1839.

Bowman JL. 2004. Class III HD-Zip gene regulation, the golden fleece of ARGONAUTE activity? Bioessays 26: 938-942.

Braun N, Wyrzykowska J, Muller P, David K, Couch D, Perrot-Rechenmann C, Fleming AJ. 2008. Conditional repression of AUXIN BINDING PROTEIN1 reveals that it coordinates cell division and cell expansion during postembryonic shoot development in Arabidopsis and tobacco. Plant Cell 20: 2746-2762.

Byrne ME, Simorowski J, Martienssen RA. 2002. ASYMMETRIC LEAVES1 reveals knox gene redundancy in Arabidopsis. Development 129: 1957-1965.

Byrne ME, Barley R, Curtis M, Arroyo JM, Dunham M, Hudson A, Martienssen RA. 2000. Asymmetric leaves1 mediates leaf patterning and stem cell function in Arabidopsis. Nature 408: 967-971.

Candela H, Martinez-Laborda A, Micol JL. 1999. Venation pattern formation in Arabidopsis thaliana vegetative leaves. Dev Biol 205: 205-216.

Carland FM, Berg BL, FitzGerald JN, Jinamornphongs S, Nelson T, Keith B. 1999. Genetic regulation of vascular tissue patterning in Arabidopsis. Plant Cell 11: 21232137.
Carland FM, Nelson T. 2004. Cotyledon vascular pattern2mediated inositol $(1,4,5)$ triphosphate signal transduction is essential for closed venation patterns of Arabidopsis foliar organs. Plant Cell 16: 1263-1275.

Carlsbecker A, Helariutta Y. 2005. Phloem and xylem specification: Pieces of the puzzle emerge. Current Opinion Plant Biol 8: 512-517.

Champagne CE, Goliber TE, Wojciechowski MF, Mei RW, Townsley BT, Wang K, Paz MM, Geeta R, Sinha NR. 2007. Compound leaf development and evolution in the legumes. Plant Cell 19: 3369-3378.

Chandler JW, Cole M, Flier A, Grewe B, Werr W. 2007. The AP2 transcription factors DORNROSCHEN and DORNROSCHEN-LIKE redundantly control Arabidopsis embryo patterning via interaction with PHAVOLUTA. Development 134: 1653-1662.

Chen JG, Shimomura S, Sitbon F, Sandberg G, Jones AM. 2001a. The role of auxin-binding protein 1 in the expansion of tobacco leaf cells. Plant J 28: 607-617.

Chen JG, Ullah H, Young JC, Sussman MR, Jones AM. 2001b. ABP1 is required for organized cell elongation and division in Arabidopsis embryogenesis. Genes Dev 15: $902-911$.

Cheng Y, Dai X, Zhao Y. 2006. Auxin biosynthesis by the YUCCA flavin monooxygenases controls the formation of floral organs and vascular tissues in Arabidopsis. Genes Dev 20: 1790-1799.

Chitwood DH, Nogueira FT, Howell MD, Montgomery TA, Carrington JC, Timmermans MC. 2009. Pattern formation via small RNA mobility. Genes Dev 23: 549-554.

Cnops G, Neyt P, Raes J, Petrarulo M, Nelissen H, Malenica N, Luschnig C, Tietz O, Ditengou F, Palme K, et al. 2006. The TORNADO1 and TORNADO2 genes function in several patterning processes during early leaf development in Arabidopsis thaliana. Plant Cell 18: 852-866.

Cole M, Chandler J, Weijers D, Jacobs B, Comelli P, Werr W. 2009. DORNROSCHEN is a direct target of the auxin response factor MONOPTEROS in the Arabidopsis embryo. Development 136: 1643-1651.

Cooke TJ, Poli D, Sztein AE, Cohen JD. 2002. Evolutionary patterns in auxin action. Plant Mol Biol 49: 319-338.

de Reuille PB, Bohn-Courseau I, Ljung K, Morin H, Carraro N, Godin C, Traas J. 2006. Computer simulations reveal properties of the cell-cell signaling network at the shoot apex in Arabidopsis. Proc Natl Acad Sci 103: 1627-1632.

DeMason DA. 2005. Auxin-cytokinin and auxin-gibberellin interactions during morphogenesis of the compound leaves of pea (Pisum sativum). Planta 222: 151-166.

DeMason DA, Chawla R. 2004. Roles for auxin during morphogenesis of the compound leaves of pea (Pisum sativum). Planta 218: 435-448.

Dengler N, Kang J. 2001. Vascular patterning and leaf shape. Current Opinion Plant Biol 4: 50-56.

Dengler NG, Tsukaya H. 2001. Leaf morphogenesis in dicotyledons- current issues. Int J Plant Sci 162: 729745 .

Deyholos MK, Cordner G, Beebe D, Sieburth LE. 2000. The $S C A R F A C E$ gene is required for cotyledon and leaf vein patterning. Development 127: 3205-3213.

Dharmasiri N, Dharmasiri S, Weijers D, Lechner E, Yamada M, Hobbie L, Ehrismann JS, Jurgens G, Estelle M. 2005. 
Plant development is regulated by a family of auxin receptor F box proteins. Develop cell 9: 109-119.

Donnelly PM, Bonetta D, Tsukaya H, Dengler RE, Dengler NG. 1999. Cell cycling and cell enlargement in developing leaves of Arabidopsis. Dev Biol 215: 407-419.

Efroni I, Blum E, Goldshmidt A, Eshed Y. 2008. A protracted and dynamic maturation schedule underlies Arabidopsis leaf development. Plant Cell 20: 2293-2306.

Esau K. 1943. Origin and development of primary vascular tissues in plants. Bot Rev 9: 125-206.

Esau K. 1965. Plant anatomy. John Wiley, New York.

Evans MM. 2007. The indeterminate gametophytel gene of maize encodes a LOB domain protein required for embryo Sac and leaf development. Plant Cell 19: 46-62.

Fahlgren N, Montgomery TA, Howell MD, Allen E, Dvorak SK, Alexander AL, Carrington JC. 2006. Regulation of AUXIN RESPONSE FACTOR3 by TAS3 ta-siRNA affects developmental timing and patterning in Arabidopsis. Curr Biol 16: 939-944.

Foster AS. 1952. Foliar Venation in Angiosperms from an Ontogenetic Standpoint. Am JBot 39: 752-766.

Fukuda H. 2004. Signals that control plant vascular cell differentiation. Nat Rev 5: 379-391.

Furutani M, Vernoux T, Traas J, Kato T, Tasaka M, Aida M. 2004. PIN-FORMED1 and PINOID regulate boundary formation and cotyledon development in Arabidopsis embryogenesis. Development 131: 5021-5030.

Galinha C, Hofhuis H, Luijten M, Willemsen V, Blilou I, Heidstra R, Scheres B. 2007. PLETHORA proteins as dose-dependent master regulators of Arabidopsis root development. Nature 449: 1053-1057.

Galweiler L, Guan C, Muller A, Wisman E, Mendgen K, Yephremov A, Palme K. 1998. Regulation of polar auxin transport by AtPIN1 in Arabidopsis vascular tissue. Science 282: 2226-2230.

Garcia D, Collier SA, Byrne ME, Martienssen RA. 2006. Specification of leaf polarity in Arabidopsis via the transacting siRNA pathway. Curr Biol 16: 933-938.

Guo M, Thomas J, Collins G, Timmermans MC. 2008. Direct repression of KNOX loci by the ASYMMETRIC LEAVES1 complex of Arabidopsis. Plant Cell 20: 48-58.

Haber AH. 1962. Effects of Indoleacetic Acid on Growth Without Mitosis \& on Mitotic Activity in Absence of Growth by Expansion. Plant Physiol 37: 18-26.

Hardtke CS, Berleth T. 1998. The Arabidopsis gene MONOPTEROS encodes a transcription factor mediating embryo axis formation and vascular development. The EMBO J 17: 1405-1411.

Hardtke CS, Ckurshumova W, Vidaurre DP, Singh SA, Stamatiou G, Tiwari SB, Hagen G, Guilfoyle TJ, Berleth T. 2004. Overlapping and non-redundant functions of the Arabidopsis auxin response factors MONOPTEROS and NONPHOTOTROPIC HYPOCOTYL 4. Development 131: $1089-1100$.

Hareven D, Gutfinger T, Parnis A, Eshed Y, Lifschitz E. 1996. The making of a compound leaf: Genetic manipulation of leaf architecture in tomato. Cell 84: 735-744.

Hay A, Tsiantis M. 2006. The genetic basis for differences in leaf form between Arabidopsis thaliana and its wild relative Cardamine hirsuta. Nat Gen 38: 942-947.
Hay A, Barkoulas M, Tsiantis M. 2006. ASYMMETRIC LEAVES1 and auxin activities converge to repress BREVIPEDICELLUS expression and promote leaf development in Arabidopsis. Development 133: 3955-3961.

Heisler MG, Ohno C, Das P, Sieber P, Reddy GV, Long JA, Meyerowitz EM. 2005. Patterns of auxin transport and gene expression during primordium development revealed by live imaging of the Arabidopsis inflorescence meristem. Curr Biol 15: 1899-1911.

Hibara K, Karim MR, Takada S, Taoka K, Furutani M, Aida M, Tasaka M. 2006. Arabidopsis CUP-SHAPED COTYLEDON3 regulates postembryonic shoot meristem and organ boundary formation. Plant Cell 18: 2946-2957.

Hunter C, Willmann MR, Wu G, Yoshikawa M, de la Luz Gutierrez-Nava M, Poethig SR. 2006. Trans-acting siRNA-mediated repression of ETTIN and ARF4 regulates heteroblasty in Arabidopsis. Development 133: 2973-2981.

Izhaki A, Bowman JL. 2007. KANADI and class III HD-Zip gene families regulate embryo patterning and modulate auxin flow during embryogenesis in Arabidopsis. Plant Cell 19: 495-508.

Jackson D, Veit B, Hake S. 1994. Expression of maize KNOTTED-1 related homeobox genes in the shoot apical meristem predicts patterns of morphogenesis in the vegetative shoot. Development 120: 405-413.

Jonsson H, Heisler MG, Shapiro BE, Meyerowitz EM, Mjolsness E. 2006. An auxin-driven polarized transport model for phyllotaxis. Proc Natl Acad Sci 103: 1633-1638.

Kang J, Dengler N. 2002. Cell cycling frequency and expression of the homeobox gene ATHB-8 during leaf vein development in Arabidopsis. Planta 216: 212-219.

Kang J, Dengler N. 2004. Vein pattern development in adult leaves of Arabidopsis thaliana. Int J Plant Sci 165: 231-242.

Kang J, Mizukami Y, Wang H, Fowke L, Dengler NG. 2007. Modification of cell proliferation patterns alters leaf vein architecture in Arabidopsis thaliana. Planta 226: 1207-1218.

Koenig D, Bayer E, Kang J, Kuhlemeier C, Sinha N. 2009. Auxin patterns Solanum lycopersicum leaf morphogenesis. Development 136: 2997-3006.

Koizumi K, Sugiyama M, Fukuda H. 2000. A series of novel mutants of Arabidopsis thaliana that are defective in the formation of continuous vascular network: Calling the auxin signal flow canalization hypothesis into question. Development 127: 3197-3204.

Kramer EM. 2004. PIN and AUX/LAX proteins: Their role in auxin accumulation. Trends Plant Sci 9: 578-582.

Leyser O. 2006. Dynamic integration of auxin transport and signalling. Curr Biol 16: R424-433.

Ljung K, Bhalerao RP, Sandberg G. 2001. Sites and homeostatic control of auxin biosynthesis in Arabidopsis during vegetative growth. Plant J 28: 465-474.

Long JA, Moan EI, Medford JI, Barton MK. 1996. A member of the KNOTTED class of homeodomain proteins encoded by the STM gene of Arabidopsis. Nature 379: 66-69.

Mattsson J, Ckurshumova W, Berleth T. 2003. Auxin signaling in Arabidopsis leaf vascular development. Plant Physiol 131: 1327-1339. 
Mattsson J, Sung ZR, Berleth T. 1999. Responses of plant vascular systems to auxin transport inhibition. Development 126: $2979-2991$.

McSteen P. 2010. Auxin and monocot development. Cold Spring Harb Perspect Biol 2: a001479.

Michniewicz M, Brewer PB, Friml J. 2007. Polar auxin transport and asymmetric auxin distribution. In The Arabidopsis Book (ed. Somerville EMMCR). American Society of Plant Biologists, Rockville, MD.

Mitchison GJ. 1980. Model for Vein Formation in HigherPlants. Proc Roy Soc London Series B-Biol Sci 207: 79-109.

Motose H, Sugiyama M, Fukuda H. 2004. A proteoglycan mediates inductive interaction during plant vascular development. Nature 429: 873-878.

Naramoto S, Sawa S, Koizumi K, Uemura T, Ueda T, Friml J, Nakano A, Fukuda H. 2009. Phosphoinositidedependent regulation of VAN3 ARF-GAP localization and activity essential for vascular tissue continuity in plants. Development 136: 1529-1538.

Nelson T, Dengler N. 1997. Leaf vascular pattern formation. Plant Cell 9: 1121-1135.

Nikovics K, Blein T, Peaucelle A, Ishida T, Morin H, Aida M, Laufs P. 2006. The balance between the MIR164A and CUC2 genes controls leaf margin serration in Arabidopsis. Plant Cell 18: 2929-2945.

Okada K, Ueda J, Komaki MK, Bell CJ, Shimura Y. 1991. Requirement of the auxin polar transport system in early stages of Arabidopsis floral bud formation. Plant Cell 3: 677-684.

Ori N, Cohen AR, Etzioni A, Brand A, Yanai O, Shleizer S, Menda N, Amsellem Z, Efroni I, Pekker I, et al. 2007. Regulation of LANCEOLATE by miR319 is required for compound-leaf development in tomato. Nat Gen 39: 787-791.

Ori N, Eshed Y, Chuck G, Bowman JL, Hake S. 2000. Mechanisms that control knox gene expression in the Arabidopsis shoot. Development 127: 5523-5532.

Pekker I, Alvarez JP, Eshed Y. 2005. Auxin response factors mediate Arabidopsis organ asymmetry via modulation of KANADI activity. Plant Cell 17: 2899-2910.

Petrasek J, Mravec J, Bouchard R, Blakeslee JJ, Abas M, Seifertova D, Wisniewska J, Tadele Z, Kubes M, et al. 2006. PIN proteins perform a rate-limiting function in cellular auxin efflux. Science 312: 914-918.

Petricka JJ, Nelson TM. 2007. Arabidopsis nucleolin affects plant development and patterning. Plant Physiol 144: 173-186.

Pray TR. 1955. Foliar venation of Angiosperms. IV. Histogenesis of the venation of Hosta. Am J Bot 42: 698-706.

Przemeck GK, Mattsson J, Hardtke CS, Sung ZR, Berleth T. 1996. Studies on the role of the Arabidopsis gene MONOPTEROS in vascular development and plant cell axialization. Planta 200: 229-237.

Reinhardt D, Mandel T, Kuhlemeier C. 2000. Auxin regulates the initiation and radial position of plant lateral organs. Plant Cell 12: 507-518.

Reinhardt D, Pesce ER, Stieger P, Mandel T, Baltensperger K, Bennett M, Traas J, Friml J, Kuhlemeier C. 2003. Regulation of phyllotaxis by polar auxin transport. Nature 426: 255-260.
Rolland-Lagan AG, Prusinkiewicz P. 2005. Reviewing models of auxin canalization in the context of leaf vein pattern formation in Arabidopsis. Plant J 44: 854-865.

Sachs T. 1968. On determination of pattern of vascular tissues in peas. Ann Bot 32: 781-790.

Sachs T. 1981. The control of the patterned differentiation of vascular tissues. Adv Bot Res 9: 151-262.

Sachs T. 1989. The development of vascular networks during leaf development. Current Topics Plant Bioch Physiol 8: 168-183.

Sawchuk MG, Donner TJ, Head P, Scarpella E. 2008. Unique and Overlapping Expression Patterns among Members of Photosynthesis-Associated Nuclear Gene Families in Arabidopsis. Plant Physiol 148: 1908-1924.

Sawchuk MG, Head P, Donner TJ, Scarpella E. 2007. Timelapse imaging of Arabidopsis leaf development shows dynamic patterns of procambium formation. New Phytol 176: $560-571$.

Scarpella E, Francis P, Berleth T. 2004. Stage-specific markers define early steps of procambium development in Arabidopsis leaves and correlate termination of vein formation with mesophyll differentiation. Development 131: 3445-3455.

Scarpella E, Marcos D, Friml J, Berleth T. 2006. Control of leaf vascular patterning by polar auxin transport. Genes Dev 20: 1015-1027.

Schruff MC, Spielman M, Tiwari S, Adams S, Fenby N, Scott RJ. 2006. The AUXIN RESPONSE FACTOR 2 gene of Arabidopsis links auxin signalling, cell division, and the size of seeds and other organs. Development 133: 251-261.

Schuetz M, Berleth T, Mattsson J. 2008. Multiple MONOPTEROS-dependent pathways are involved in leaf initiation. Plant Physiol 148: 870-880.

Semiarti E, Ueno Y, Tsukaya H, Iwakawa H, Machida C, Machida Y. 2001. The ASYMMETRIC LEAVES2 gene of Arabidopsis thaliana regulates formation of a symmetric lamina, establishment of venation and repression of meristem-related homeobox genes in leaves. Development 128: 1171-1183.

Sieburth LE. 1999. Auxin is required for leaf vein pattern in Arabidopsis. Plant Physiol 121: 1179-1190.

Smith RS, Guyomarc'h S, Mandel T, Reinhardt D, Kuhlemeier C, Prusinkiewicz P. 2006. A plausible model of phyllotaxis. Proc Natl Acad Sci 103: 1301-1306.

Snow M, Snow R. 1937. Auxin and leaf formation. New Phytol 36: $1-18$.

Steeves TA, Sussex IM. 1989. Patterns in plant development. Cambridge University press, Cambridge.

Steynen QJ, Schultz EA. 2003. The FORKED genes are essential for distal vein meeting in Arabidopsis. Development 130: $4695-4708$.

Takada S, Hibara K, Ishida T, Tasaka M. 2001. The CUPSHAPED COTYLEDON1 gene of Arabidopsis regulates shoot apical meristem formation. Development 128: 1127-1135.

Timmermans MC, Hudson A, Becraft PW, Nelson T. 1999. ROUGH SHEATH2: A Myb protein that represses knox homeobox genes in maize lateral organ primordia. Science 284: 151-153. 
Tsiantis M, Brown MI, Skibinski G, Langdale JA. 1999a Disruption of auxin transport is associated with aberrant leaf development in maize. Plant Physiol 121: $1163-1168$.

Tsiantis M, Schneeberger R, Golz JF, Freeling M, Langdale JA. 1999b. The maize rough sheath2 gene and leaf development programs in monocot and dicot plants. Science 284: 154-156.

Vernoux T, Kronenberger J, Grandjean O, Laufs P, Traas J. 2000. PIN-FORMED 1 regulates cell fate at the periphery of the shoot apical meristem. Development 127: 5157-5165.

Vroemen CW, Mordhorst AP, Albrecht C, Kwaaitaal MA, de Vries SC. 2003. The CUP-SHAPED COTYLEDON3 gene is required for boundary and shoot meristem formation in Arabidopsis. Plant Cell 15: 1563-1577.

Waites R, Selvadurai HR, Oliver IR, Hudson A. 1998. The PHANTASTICA gene encodes a MYB transcription factor involved in growth and dorsoventrality of lateral organs in Antirrhinum. Cell 93: 779-789.

Wang H, Jones B, Li Z, Frasse P, Delalande C, Regad F, Chaabouni S, Latche A, Pech JC, Bouzayen M. 2005. The tomato $A u x / I A A$ transcription factor IAA9 is involved in fruit development and leaf morphogenesis. Plant Cell 17: $2676-2692$.
Wenzel CL, Schuetz M, Yu Q, Mattsson J. 2007. Dynamics of MONOPTEROS and PIN-FORMED1 expression during leaf vein pattern formation in Arabidopsis thaliana. Plant J 49: 387-398.

Wilmoth JC, Wang S, Tiwari SB, Joshi AD, Hagen G, Guilfoyle TJ, Alonso JM, Ecker JR, Reed JW. 2005. NPH4/ ARF7 and ARF19 promote leaf expansion and auxin-induced lateral root formation. Plant J 43: 118-130.

Wisniewska J, Xu J, Seifertova D, Brewer PB, Ruzicka K, Blilou I, Rouquie D, Benkova E, Scheres B, Friml J. 2006. Polar PIN localization directs auxin flow in plants. Science 312: 883.

Xu L, Xu Y, Dong A, Sun Y, Pi L, Xu Y, Huang H. 2003. Novel as1 and as2 defects in leaf adaxial-abaxial polarity reveal the requirement for ASYMMETRIC LEAVES1 and 2 and ERECTA functions in specifying leaf adaxial identity. Development 130: 4097-4107.

Zgurski JM, Sharma R, Bolokoski DA, Schultz EA. 2005. Asymmetric auxin response precedes asymmetric growth and differentiation of asymmetric leaf1 and asymmetric leaf2 Arabidopsis leaves. Plant Cell 17: 77-91.

Zhang J, Chen R, Xiao J, Qian C, Wang T, Li H, Ouyang B, Ye Z. 2007. A single-base deletion mutation in SlIAA9 gene causes tomato (Solanum lycopersicum) entire mutant. J Plant Res 120: 671-678. 


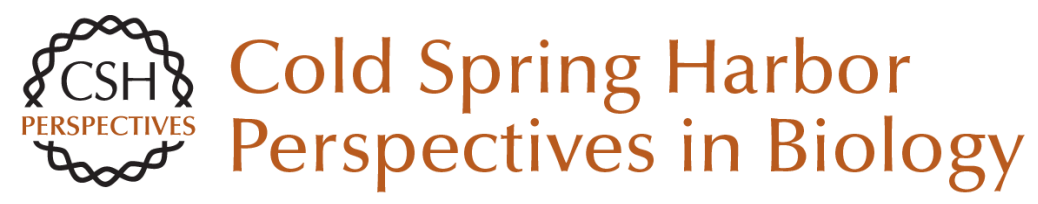

\section{Control of Leaf and Vein Development by Auxin}

Enrico Scarpella, Michalis Barkoulas and Miltos Tsiantis

Cold Spring Harb Perspect Biol 2010; doi: 10.1101/cshperspect.a001511 originally published online December 2, 2009

\section{Subject Collection Auxin Signaling}

Fourteen Stations of Auxin Jirí Friml

Computational Models of Auxin-Driven Patterning in Shoots

Mikolaj Cieslak, Andrew Owens and Przemyslaw Prusinkiewicz

Auxin Transporters--A Biochemical View Ulrich Z. Hammes, Angus S. Murphy and Claus Schwechheimer

Structural Aspects of Auxin Signaling Nicholas Morffy and Lucia C. Strader

The Story of Auxin-Binding Protein 1 (ABP1) Richard Napier

Noncanonical Auxin Signaling Heather Marie McLaughlin, Aaron Chun Hou Ang and Lars Østergaard

Casting the Net--Connecting Auxin Signaling to the Plant Genome Yanfei Ma, Sebastian Wolf and Jan U. Lohmann

Auxin Plays Multiple Roles during Plant-Pathogen Interactions

Barbara N. Kunkel and Joshua M.B. Johnson
Auxin in Root Development

Suruchi Roychoudhry and Stefan Kepinski

Modeling Auxin Signaling in Roots: Auxin Computations

Jaap Rutten, Thea van den Berg and Kirsten ten Tusscher

The Systems and Synthetic Biology of Auxin $R$. Clay Wright, Britney L. Moss and Jennifer L. Nemhauser

Auxin Does the SAMba: Auxin Signaling in the

Shoot Apical Meristem Markéta Pernisová and Teva Vernoux

Chemical Biology in Auxin Research Ken-ichiro Hayashi

Uncovering How Auxin Optimizes Root Systems

Architecture in Response to Environmental

Stresses Nicola Leftley, Jason Banda, Bipin Pandey, et al.

Auxin Interactions with Other Hormones in Plant Development

Serina M. Mazzoni-Putman, Javier Brumos, Chengsong Zhao, et al.

No Time for Transcription--Rapid Auxin

Responses in Plants

Shiv Mani Dubey, Nelson B.C. Serre, Denisa Oulehlová, et al.

For additional articles in this collection, see http://cshperspectives.cshlp.org/cgi/collection/

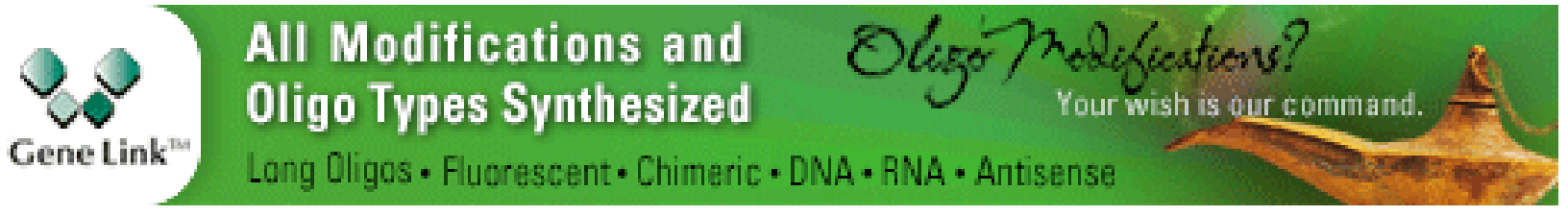

Copyright @ 2010 Cold Spring Harbor Laboratory Press; all rights reserved 
For additional articles in this collection, see http://cshperspectives.cshlp.org/cgi/collection/

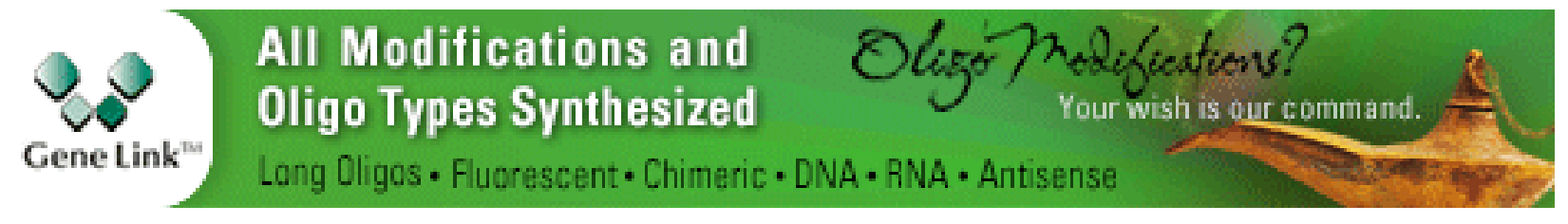

Copyright @ 2010 Cold Spring Harbor Laboratory Press; all rights reserved 